\title{
Non-Communicating Hydrocephalus
}

National Cancer Institute

\section{Source}

National Cancer Institute. Non-Communicating Hydrocephalus. NCI Thesaurus. Code C116347.

An abnormal accumulation of cerebrospinal fluid within the ventricles of the brain that occurs as a consequence of an obstruction at any location within the ventricular system that prevents cerebrospinal fluid flowing into the subarachnoid space. 